\title{
Theoretical and Numerical Analyses in Hybrid Ti/APC-2 Composite Laminates Due to High Velocity Impact
}

\author{
Ming-Hwa R Jen, Che-Kai Chang*, Shang-Meng Liu and Kuan-Hua Lai \\ Department of Mechanical and Electro-Mechanical Engineering, National Sun Yat-Sen University, Taiwan
}

Submitted: October 02, 2017; Published: November 10, 2017

*Corresponding author: Che-Kai Chang, Department of Mechanical and Electro-Mechanical Engineering, National Sun Yat-Sen University, Taiwan, Email: d993020009@student.nsysu.edu.tw

\begin{abstract}
Fiber/metal composites (FMCs) have attracted much attention over twenty years, especially in the applications to aerospace and aeromechanical structures. In addition to their advantages of fiber reinforced composites they also possess superior resistance to cyclic loadings. It is well-known known that conventionally the composite laminates are weak due to out-of-plane loads. Hence, vulnerability against high velocity impact loads is becoming an increasingly critical issue for the design of FMCs in aerospace structures recently. In this study we mainly focus on the theoretical derivations of penetration and perforation in Ti/APC-2 hybrid composite laminates impacted by a hemispherenose cylindrical projectile at high velocities, and verifies the results by numerical simulation, such as finite element method and ANSYS LS DYNA 3D software.
\end{abstract}

Fundamentally, cross-ply $[0 / 90] 4 \mathrm{~s}$ and quasi-isotropic [0/ $\pm 45 / 90] 2 \mathrm{~S} \mathrm{APC}-2$ composite laminates are investigated. Then, Ti/APC-2 hybrid laminates are studied as an extensional work based on previous experience. It is quite different from the cases of low velocity impact that the boundary conditions and geometry of laminated plate can be omitted, and the wave propagation model should be used in high velocity impact. Thus, a rectangular composite laminate is analyzed for general purposes. The theoretical process involves first the deformation and failure of face sheets, through-thickness propagation of shock wave into the middle plies of shear failure, fracture of back sheets and perforation finally. Equations of motion for the projectile and effective masses of the face sheets, middle plies and back sheets as shock wave traveling through the whole laminate are derived by using Lagrangian mechanics. The analytical approach is mechanistic involving no detail account of progressive damage due to cracking, delamination and debonding, etc.

Analytical predictions of total time of traveling ballistic limit, (perforation of laminate with zero residual velocity), residual velocity, transient deflection and velocities of projectile are determined. They are compared with the results from numerical simulation within acceptable errors. Both methods provide valuable achievements that makes us thoroughly understand the phenomena of high velocity impact in composite laminates.

Keywords: High velocity; Impact; Hybrid; Composite laminate; Penetration; Perforation; Ballistic limit; Residual velocity

\section{Introduction}

Fiber metal laminates (FMLs) are hybrid structures basically composed of thin metal sheets bonded together with layers of polymer matrix composites [1-3] provided comprehensive reviews of the research and development of these materials. In the early 80s, FMLs were developed at the Delft University in Netherlands. They introduced ARALL (Aramid fiber reinforced aluminum laminate). Later, the second generation of FML, i.e. GLARE, was created in 1987. The GLARE was designed to improve ARALL laminates and commercialized at early $90 \mathrm{~s}$. Impact damage is an important failure type in aircraft structures. It is reported at least $13 \%$ of 688 repairs of Boeing 747 fuselages related to impact damage [4]. Impact damage of aircraft is caused by both high and low speed impacts that results in different impact mechanisms should be considered during the design process for safety. In the last decade, the use of GLARE has been expanded because of its improved impact properties reported by [5] for high-velocity impact, such that for GLARE a $15 \%$ increase in the ballistic limit was observed compared to bare 2024 aluminum with the same areal density.

The early generation FMLs was based on composites with thermosetting polymer matrices. However, their main disadvantages are the long curing process and low glass transition temperature (Tg). In contrast, FMLs with thermoplastic based composites offer a superior resistance to aggressive environments, outstanding interlaminar fracture properties, excellent resistance to both low and high velocity impact loadings, short process time to cure $[6,7]$, and potentially wide applications. For longer term bond durability, anodic 
method is a commonly used surface treatment. The chromic acid anodizing (CAA) surface treatment method creates a stable and porous oxide on the Aluminum and Titanium surfaces.

There have been existed numerous studies on high velocity impact in composite materials recently. However, the research work on high velocity impact in sandwich structures and hybrid fiber/metal composites is still not sufficient. The related investigations are cited for example [8]. Studied the response of composite and FML-reinforced sandwich structures caused by the velocity impact [9]. Detected and characterized the velocity impact damage in advanced composite plates by using multisensing technology [10]. Did numerical modeling and simulation of foam-cored sandwich plates under high velocity impact [11] established a wave propagation model for the high velocity impact response of a composite sandwich panel theoretically and numerically [12]. Performed penetration of a woven CFRP laminate up to the velocity of $1875 \mathrm{~m} / \mathrm{s}$.

Our work focuses on the high velocity impact in FMLs from thin to thick laminates to investigate the failure mechanisms layer by layer and obtain the ballistic limit (i.e., residual velocity is approximately zero just after penetration) for each FML.

\section{Materials}

The samples used in simulation were divided into two parts: such as Carbon fiber/PEEK (APC-2) cross-ply composite laminates, and APC-2 cross-ply laminates sandwiched by Titanium sheets as hybrid FMLs. Generally, both laminates are symmetrically oriented with respect to the center line. To resist high velocity impact the thicknesses of the laminates were varied from thin to thick (i.e., for [0/90]3S 12 lay-ups $t=1.55 \mathrm{~mm}$ up to 72 lay-ups of $0.99 \mathrm{~cm}$ and more). The dimensions of rectangular samples were L W $\mathrm{t}=240 \mathrm{~mm} 25 \mathrm{~mm} \mathrm{t}$. The thickness of Ti sheets is $0.5 \mathrm{~mm}$. The radius of a bullet, as rigid impactor, is $5 \mathrm{~mm}$. From our previous research work the mechanical properties, such as stiffness and ultimate tensile strength of both APC2 laminates and FMLs were directly obtained from [13-15], adopted as the input data for numerical simulation. As for the thick laminates their mechanical properties can be reasonably and indirectly received by using the rule of mixtures. The mechanical properties of both impactor, bullet, and target hybrid composite laminate, Ti/ [0/90] S/Ti, are listed in Table 1.

Table 1: The mechanical properties of both impactor, bullet, and target hybrid composite laminate.

\begin{tabular}{|c|c|c|c|c|}
\hline Material & $\begin{array}{c}\text { Density } \\
\text { (kg/m3) }\end{array}$ & $\begin{array}{c}\text { Ultimate } \\
\text { Strength } \\
\text { (MPa) }\end{array}$ & $\begin{array}{c}\text { Stiffness } \\
\text { (GPa) }\end{array}$ & $\begin{array}{c}\text { Shear } \\
\text { Modulus } \\
\text { G(GPa) }\end{array}$ \\
\hline Bullet & 7769 & 2240 & 195 & 80 \\
\hline $\begin{array}{c}\text { APC-2 } \\
\text { cross-ply } \\
\text { laminates }\end{array}$ & 1600 & 916.4 & 78.7 & 5.4 \\
\hline Ti sheet & 4438 & 108.8 & 352 & 45 \\
\hline
\end{tabular}

\section{Numerical Analysis}

We modeled a hard steel bullet impactor onto a target hybrid composite laminate at high velocity by using three-dimensional finite element method and ANSYS/LS-DYNA-3D software in numerical simulation. The geometry, dimensions and boundary conditions (BCs) for a quarter hybrid composite laminate, because of the loading impact at the center of laminate, are shown in Figure 1. In order to simulate the penetration and perforation processes, numerical simulations using LS-DYNA-3D were made for the same configurations as the previous investigations of low velocity impact by both simulations and experiments. Also, there is no any restrictions on the $\mathrm{BCs}$ of target laminate due to high velocity impact, i.e., simply supported BCs for hybrid laminates are appropriate.

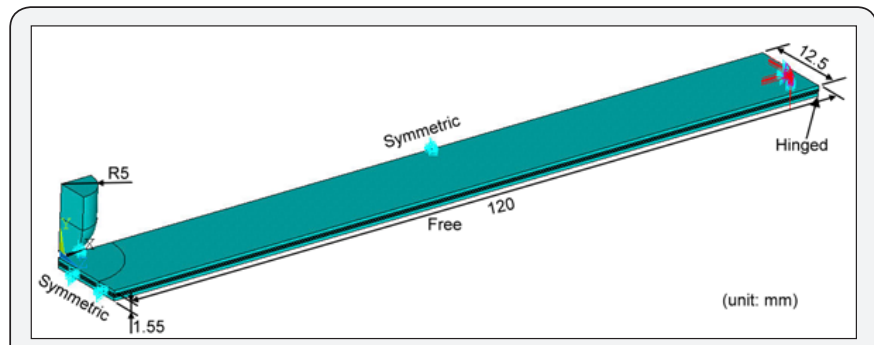

Figure 1: The geometry, dimensions and BCs for a quarter hybrid composite laminate with the load impacted at the center of laminate.

Computational penetration mechanics modeling of composites is a relatively complex subject, which requires defining the fiber and matrix dominated damage modes, rate effects on material properties, and one or more element erosion criteria, especially designed to model ballistic penetration of thick-section composites in three dimensions [16]. Thus, it took mush time to complete the simulation of one case.

\section{Results}

Table 2: The dimensions and total element number for the quarter of lay-ups of APC-2 and hybrid APC-2 laminates.

\begin{tabular}{|c|c|c|c|}
\hline $\begin{array}{l}\text { Composite } \\
\text { Laminates }\end{array}$ & Layups & Thickness(Mm) & $\begin{array}{c}\text { Total } \\
\text { Elements } \\
\text { Numbers }\end{array}$ \\
\hline \multirow{6}{*}{ APC-2 } & 12 & 1.65 & 56184 \\
\hline & 24 & 3.3 & 115296 \\
\hline & 36 & 4.95 & 171432 \\
\hline & 48 & 6.6 & 229920 \\
\hline & 60 & 8.25 & 285720 \\
\hline & 72 & 9.9 & 344448 \\
\hline \multirow{4}{*}{ Hybrid APC-2 } & 3 & 1.55 & 77376 \\
\hline & 5 & 2.6 & 128520 \\
\hline & 9 & 4.7 & 231624 \\
\hline & 17 & 8.9 & 433976 \\
\hline \multicolumn{4}{|c|}{ Note: Length $=120 \mathrm{~mm}$ Width $=12.5 \mathrm{~mm}$} \\
\hline
\end{tabular}


Table 3: The impact velocity and residual velocity after impact associated with the corresponding energy for (a) APC-2 cross-ply [0/90]3S 12 layups, (b) Ti/[0/90]S/Ti 3 layups, (c) $\left[\mathrm{Ti} /(0 / 90)_{2} /\right.$ ] 5 layups, (d) $\left[\mathrm{Ti} /(0 / 90) 2 / \mathrm{Ti} /(0 / 90)_{2} /\right] \mathrm{S} 9$ layups, and $(\mathrm{e})\left[\mathrm{Ti} /(0 / 90)_{2} 2 / \mathrm{Ti} /(0 / 90)_{2} / \mathrm{Ti} /(0 / 90)_{2} /\right] \mathrm{S} 17$ layups composite laminates.

\begin{tabular}{|c|c|c|c|c|c|}
\hline \multicolumn{3}{|c|}{ Impact } & After Impact & \multicolumn{2}{|c|}{ The Difference } \\
\hline Velocity $(\mathrm{m} / \mathrm{s})$ & Energy (J) & Velocity $(\mathrm{m} / \mathrm{s})$ & Energy (J) & Velocity Difference $(\mathrm{m} / \mathrm{s})$ & $\begin{array}{c}\text { Energy } \\
\text { Difference (J) }\end{array}$ \\
\hline \multicolumn{6}{|c|}{ (a) } \\
\hline 100 & 6.34 & 95.5 & 5.75 & 4.5 & 0.59 \\
\hline 200 & 25.4 & 195 & 24.1 & 5 & 1.3 \\
\hline 500 & 158.6 & 493 & 154.1 & 7 & 4.5 \\
\hline 1000 & 634.5 & 990.5 & 622.2 & 9.5 & 12 \\
\hline 1500 & 1425.5 & 1488.2 & 1405 & 11.8 & 20.5 \\
\hline 2000 & 2535.5 & 1986.5 & 2500.7 & 13.5 & 34.8 \\
\hline \multicolumn{6}{|c|}{ (b) } \\
\hline 200 & 25.5 & 129.3 & 10.3 & 70.7 & 15.2 \\
\hline 500 & 158.5 & 474.8 & 142.9 & 25.2 & 15.6 \\
\hline 1000 & 634.5 & 963.5 & 592.6 & 36.5 & 41.9 \\
\hline 1500 & 1426.2 & 1459.1 & 1350.2 & 40.9 & 76 \\
\hline 2000 & 2538.2 & 1955.5 & 2425.3 & 44.48 & 112.9 \\
\hline \multicolumn{6}{|c|}{ (c) } \\
\hline 200 & 25.5 & 107.1 & 4.5 & 92.9 & 21 \\
\hline 500 & 158.5 & 462.4 & 135.4 & 37.6 & 23.1 \\
\hline 1000 & 634.5 & 950.1 & 571.8 & 49.9 & 62.7 \\
\hline 1500 & 1426.2 & 1437 & 1309.7 & 63 & 116.5 \\
\hline 2000 & 2538.2 & 1931.2 & 2365 & 68.82 & 173.2 \\
\hline \multicolumn{6}{|c|}{ (d) } \\
\hline 200 & 25.5 & --- & --- & & \\
\hline 500 & 158.5 & 435.7 & 120.4 & 64.3 & 38.1 \\
\hline 1000 & 634.5 & 916.7 & 533 & 83.3 & 101.5 \\
\hline 1500 & 1426.2 & 1393.1 & 1230.9 & 106.9 & 195.3 \\
\hline 2000 & 2538.2 & 1884 & 2251.7 & 116 & 286.5 \\
\hline \multicolumn{6}{|c|}{ (e) } \\
\hline 200 & 25.5 & --- & --- & & \\
\hline 500 & 158.5 & 373.3 & 88.5 & 126.7 & 70 \\
\hline 1000 & 634.5 & 853.9 & 462.3 & 146.1 & 172.2 \\
\hline 1500 & 1426.2 & 1310.5 & 1088.5 & 189.5 & 337.7 \\
\hline 2000 & 2538.2 & 1786.9 & 2025 & 213.1 & 513.2 \\
\hline \multicolumn{6}{|c|}{ Note: ---- = unperforated } \\
\hline
\end{tabular}

The dimensions and total element number for the lay-ups of APC-2 and hybrid APC-2 laminates are shown in Tables 2. The impact velocity and residual velocity after impact in terms of energy for various thicknesses of APC-2 [0/90]3s 12 lay-ups, Ti/ [0/90]s/Ti, [Ti/(0/90)2/ ]S, [Ti/(0/90)2/Ti/(0/90)2/ ]S, and $[\mathrm{Ti} /(0 / 90) 2 / \mathrm{Ti} /(0 / 90) 2 / \mathrm{Ti} /(0 / 90) 2 /] \mathrm{S}$ hybrid laminates are tabulated in Tables $3(\mathrm{a}-\mathrm{e})$, respectively.

In order to final the ballistic limit of composite laminates with increasing velocity we have to increase the thickness of laminates. Those laminates can resist high velocity impact through the process of penetration and perforation with approximately zero velocity at leaving the target laminate. The ballistic limits of both APC-2 and hybrid APC-2 laminates due to impact velocities are listed in Table 4. It is obvious to see that hybrid APC-2 laminates possess higher impact resistance than that of APC- 2 laminates. The failure mechanisms of APC-2 12 lay-ups and Ti/APC-2 3 layups composite laminates are shown in Figure 2(a) and Figure 2(b), respectively. Similarly, the failure mechanisms of APC-2 72 lay-ups and Ti/APC-2/Ti 17 lay-ups laminates are presented in Figure 3(a) and Figure 3(b), respectively. 
Table 4: The impact velocity for varied thickness of APC-2 and hybrid APC-2 composite laminates resulted in the ballistic limit. (i.e.,Vresidual=0).

\begin{tabular}{|c|c|c|c|}
\hline Composite Laminates & Sample & Layups & Impact Velocity $(\mathrm{m} / \mathrm{s})$ \\
\hline \multirow{6}{*}{ APC-2 } & {$[0 / 90]_{3 \mathrm{~S}}$} & 12 & 26 \\
\hline & {$[0 / 90]_{6 S}$} & 24 & 34 \\
\hline & {$[0 / 90]_{9 \mathrm{~S}}$} & 36 & 45 \\
\hline & {$[0 / 90]_{12 \mathrm{~S}}$} & 48 & 54 \\
\hline & {$[0 / 90]_{15 \mathrm{~s}}$} & 60 & 64 \\
\hline & {$[0 / 90]_{18 \mathrm{~s}}$} & 72 & 72 \\
\hline \multirow{4}{*}{ Hybrid APC-2 } & $\mathrm{Ti} /[0 / 90]_{S} / \mathrm{Ti}$ & 3 & 193 \\
\hline & {$\left[\mathrm{Ti} /(0 / 90)_{2} /\right] \mathrm{S}$} & 5 & 197 \\
\hline & {$\left[\mathrm{Ti} /(0 / 90) 2 / \mathrm{Ti} /(0 / 90)_{2} /\right] \mathrm{S}$} & 9 & 202 \\
\hline & $\begin{array}{c}{\left[\mathrm{Ti} /(0 / 90)_{2} / \mathrm{Ti} /(0 / 90)_{2} / \mathrm{Ti} /\right.} \\
\left.(0 / 90)_{2} / \mathrm{Ti} /(0 / 90)_{2} /\right] \mathrm{S}\end{array}$ & 17 & 303 \\
\hline \multicolumn{4}{|c|}{ Notes: The thickness of [0/90] ply is $0.275 \mathrm{~mm}$. } \\
\hline
\end{tabular}

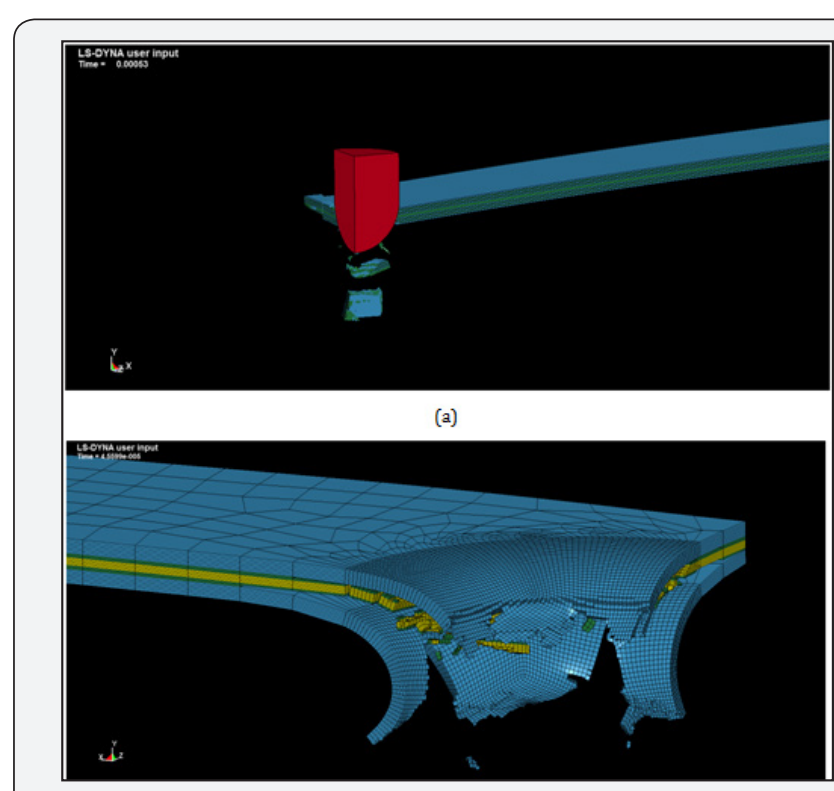

Figure 2 : The geometry, dimensions and BCs for a quarter hybrid composite laminate with the load impacted at the center of laminate.

\section{Discussion}

Based on the previous experience of low velocity impact on composite laminates the numerical simulations by FEM and LS-DYNA-3D were verified satisfactorily well with empirical data. We extended the research work to high velocity impact onto hybrid composite laminates. To assure the correctness of numerical results is the most important task. First we checked the convergence of received results, as shown in Figure 4, and compared the results with the published work, especially the data obtained by experiments. Herein, both types of laminates are of excellent bonding without delamination due to high velocity impact [13-15]. For multi-layered composites with increasing thickness from thin to thick laminates we adopted the code of single surface eroding and eroding contact for failed material element to simulate the penetration and perforation processing.

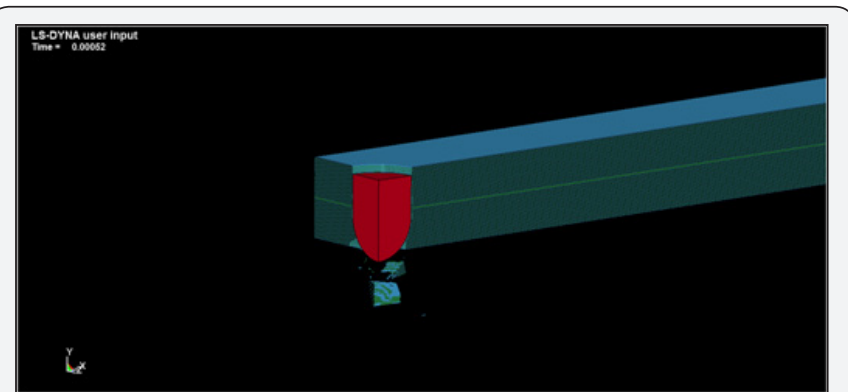

(a)

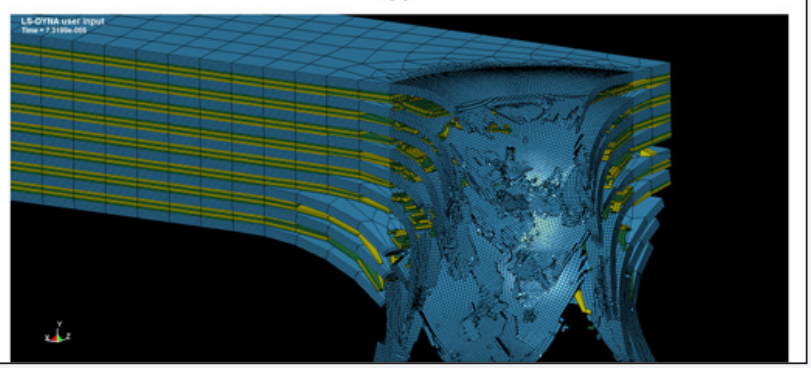

Figure 3 : The failure mechanisms of (a) APC-2 72 lay-ups and (b) Ti/APC-2/Ti 17 lay-ups composite laminates.

That is proved to be proper and suitable. Another way to prove the correctness of simulation results is to compare them with the theoretical formulation. The total wave travel time through the entire thickness of hybrid composite laminate is given below by modifying the Equations in [11] as

$$
t_{1}=\frac{2 h}{c_{d}}+\frac{H}{c_{f}}
$$

where $h$ and $\mathrm{H}$ are the thickness of $\mathrm{T}_{\mathrm{i}}$ and APC- 2 cross-ply layups, $C_{d}$ is the dilatational wave speed of $T_{i}$ sheet, i.e., cover sheet, and $\mathrm{C}_{\mathrm{f}}$ is the through-thickness wave speed in an orthotropic plate, now is cross-ply plate simply. We found both results of total travel time in acceptable errors. The travel time from impacting to just perforating the laminate is listed in Table 5. That finally demonstrates our numerical results are correct and acceptable, even if no empirical data in comparison. 
Table 5: The travel time from impacting to just perforating of both APC-2 and hybrid APC-2 laminates with different thicknesses.

\begin{tabular}{|c|c|c|c|}
\hline Composite Laminates & Sample & Impact Velocity $(\mathrm{m} / \mathrm{s})$ & Impact time $(\mathrm{m} / \mathrm{s})$ \\
\hline \multirow{6}{*}{ APC-2 } & \multirow{6}{*}{$\begin{array}{l}72 \text { layups } \\
{[0 / 90]_{18 s}}\end{array}$} & 100 & 0.29 \\
\hline & & 200 & 0.118 \\
\hline & & 500 & 0.0429 \\
\hline & & 1000 & 0.0209 \\
\hline & & 1500 & 0.0138 \\
\hline & & 2000 & 0.0102 \\
\hline \multirow{4}{*}{ Hybrid APC-2 } & \multirow{4}{*}{$\begin{array}{c}17 \text { layups } \\
{\left[\mathrm{Ti} /(0 / 90)_{2} / \mathrm{Ti} /(0 / 90)_{2} / \mathrm{Ti} /\right.} \\
\left.(0 / 90)_{2} / \mathrm{Ti} /(0 / 90)_{2} /\right]_{\mathrm{S}}\end{array}$} & 500 & 0.0456 \\
\hline & & 1000 & 0.021 \\
\hline & & 1500 & 0.014 \\
\hline & & 2000 & 0.0102 \\
\hline \multicolumn{4}{|c|}{ Notes: The thickness of [0/90] ply is $0.275 \mathrm{~mm}$. } \\
\hline \multicolumn{4}{|c|}{ The thickness of $\mathrm{T}_{\mathrm{i}}$ sheet is $0.5 \mathrm{~mm}$. } \\
\hline
\end{tabular}

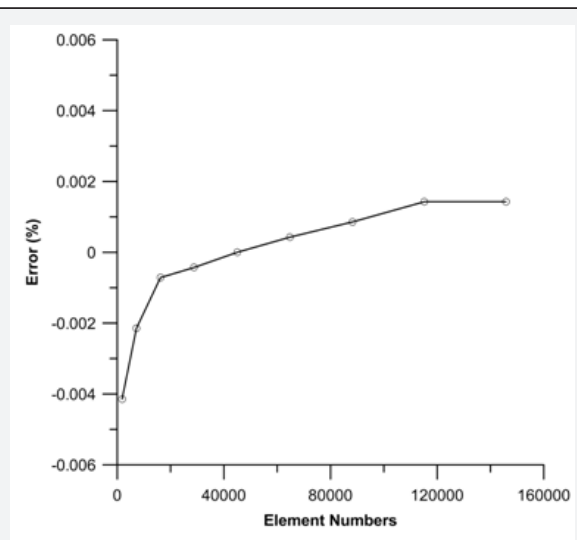

(a)

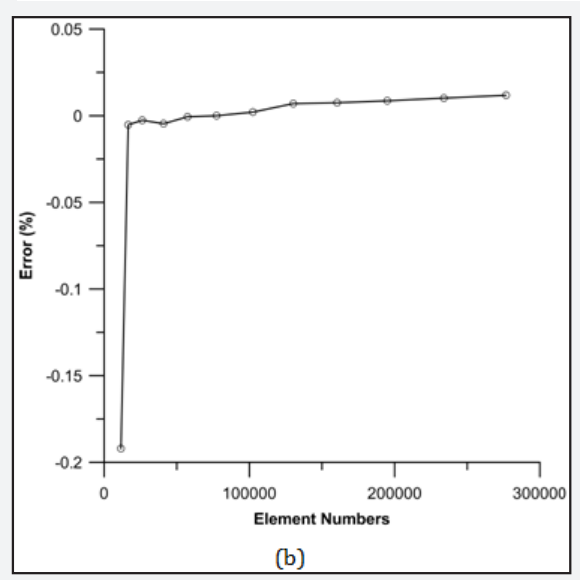

Figure 4 : The convergence of received results of (a) APC-2 12 lay-ups and (b) Ti/APC-2/Ti 3 lay-ups composite laminates.

In addition, Reid \& Wen [17] proposed an equation to predict the ballistic limit of FMLs as,

$$
V_{B}=\frac{\pi \tau \sqrt{\rho_{t} \sigma_{e}} D T}{4 m}\left[1+\sqrt{1+\frac{8 m}{\pi \tau^{2} \rho_{t} D^{2} T}}\right]
$$

where $V_{b}$ is the ballistic limit, $\rho_{t}$ is the density of laminate, $D$ is the diameter projectile, $\mathrm{T}$ is the thickness of laminate, $\mathrm{m}$ is the mass of projectile, and $\sigma_{\mathrm{e}}$ is the static linear elastic compression limit. The term $\Gamma$ is an experimentally-determined constant with a value of 1.5 for a hemispherical ended projectile. The numerical prediction in both laminates of ballistic limit is for reference.

\section{Conclusion}

Both APC-2 and hybrid APC-2 composite laminates due to high velocity impact were numerically investigated by using FEM and LS-DYNA-3D computer software's. First for specified laminates of the same thickness the hybrid laminates possess higher resistance than that of APC-2 laminates. Increasing the laminate thickness the corresponding ballistic limit also increases, however, the hybrid laminates increase their ballistic limits much higher. Finally, the numerical results were verified correctly acceptable in several ways.

\section{Acknowledgment}

The authors would like to gratefully acknowledge the sponsorship from National Science Council under the project number NSC101-2221-E110-006.

\section{References}

1. Sinmazcelik T, Avcu E, Bora MO, Caban O (2011) A review: Fibre metal laminates, background, bonding types and applied test methods. Materials \& Design 32(7): 3671-3685.

2. Vlot A, Gunnink JW (2001) Fibre metal laminates: an introduction. In: Vlot Ad, Gunnink, Jan Willem, (Eds.), Boston: Kluwer Academic Publishers, Dordrecht, Netherlands.

3. Gunnink JW, Vlot A, de Vries TJ, van der Hoeven W (2002) Glare technology development 1997-2000. Applied Composite Materials 9(4): 201-219.

4. Vlot A (1993) Impact properties of fiber metal laminates. Composite Engineering 3: 911-927.

5. Hoo Fatt MS, Lin C, Revilock DM, Hopkins DA (2003) Ballistic impact of Glare fiber -metal laminates. Composite Structures 61: 73-88.

6. Reyes VG (2002) Processing and characterisation of the mechanical properties of novel fibre-metal laminates. Liverpool: $\mathrm{PhD}$ Thesis.

7. Abdullah MR, Cantwell WJ (2006) The impact resistance of polypropylene-based fibre-metal laminates. Composites Science and Technology 66: 1682-1693. 
8. Villanueva GR, Cantwell WJ (2004) The high velocity impact response of composite and FML-reinforced sandwich structures. Composite Science and Technology 64(1): 35-54.

9. Okafor AC, Otieno AW, Dutta A, Rao VS (2001) Detection and characterization of high-velocity impact damage in advanced composite plates using multi-sensing technigues. Composite Structures 54(2-3) 289-297.

10. Ivañez I, Santiuste C, Barbero E, Sanchez-Saez S (2011) Numerical modeling of foam-cored sandwich plates under high-velocity impact. Composite Structures 93(9): 2392-2399.

11. Fatt MSH, Sirivolu D (2010) A wave propagation model for the high velocity impact response of a composite sandwich panel. Int J of impact Engr 37(2): 117-130.

12. Hazell PJ, Kister G, Stennett C, Bourque P, Cooper G (2009) Penetration of a woven CFRP laminate by a high velocity steel sphere impacting at velocities of up to 1875 m/s. Int J of impact Engr 36: 1136-1142.
13. Jen MHR, Sung YC (2012) Determination of residual strength in notched APC-2 cross-ply composite laminates at elevated temperature. J of Composite Materials 46(14): 1705-1713.

14. Jen MHR, Sung YC (2012) Prediction and verification strength in APC2 composite laminates at elevated temperature. Materials Science and Engineering A 532: 31-36.

15. Jen MHR, Che-Kai C, Jing-Guan C, Bo-Cyuan L (2012) Fatigue response of Ti/APC-2 nanocomposite laminates Prosthesis. Life Science J 9(2): 178-184.

16. Phoenix SL, Porwal PK (2003) A new membrane model for ballistic impact response and V50 performance of multi-ply fibrous systems. int J of Solids and structures 40: 6723-65.

17. Villanueva GR, Cantwell WJ (2004) The high velocity impact response of composite and FML-reinforced sandwich structures. Composites Science and Technology 64: 35-54.

\section{Your next submission with Juniper Publishers} will reach you the below assets

- Quality Editorial service

- Swift Peer Review

- Reprints availability

- E-prints Service

- Manuscript Podcast for convenient understanding

- Global attainment for your research

- Manuscript accessibility in different formats ( Pdf, E-pub, Full Text, Audio)

- Unceasing customer service

Track the below URL for one-step submission https://juniperpublishers.com/online-submission.php 